\title{
QUANTIFICAÇÃO E AVALIAÇÃO DE PARAMÊTROS QUALI- QUANTITATIVOS DO PALMITEIRO (Euterpe edulis MARTIUS), AO LONGO DE UM GRADIENTE ALTIMÉTRICO EM UM SISTEMA DE INFORMAÇÃO GEOGRÁFICA
}

\author{
Emerson Roberto Schoeninger ${ }^{1}$ \\ Flávio Felipe Kirchner ${ }^{2}$
}

\begin{abstract}
RESUMO
A presente pesquisa objetivou a caracterização dos efeitos da altitude sobre o crescimento do Palmiteiro (Euterpe edulis). Para tanto foram definidas dez unidades amostrais ao longo de um gradiente de altitude, distribuídas sistematicamente com intervalos de 500 metros em um morro na formação Rio das Cobras com um raio com de aproximadamente $1500 \mathrm{~m}$ de extensão e com uma variação de $500 \mathrm{~m}$ na altitude. Para avaliação do Palmiteiro no gradiente altimétrico foram abatidos oito indivíduos de cada nível altimétrico, dos quais foram coletados os dados de biomassa total e a biomassa do creme comestível. Quando comparados os resultados encontrou-se tendências entre a produção de biomassa total e do creme em relação ao gradiente altitudinal. O SIG foi construído para retornar os valores de biomassa total e do creme e a densidade dos indivíduos na área, o que proporcionara informações para o planejamento florestal.

Palavras chave: SIG, Nutrientes, Palmeiras, Palmito
\end{abstract}

\section{QUANTIFICATION AND EVALUATION OF QUALITATIVE AND QUANTITATIVE PARAMETERS OF PALMITEIRO (Euterpe edulis MARTIUS) ALONG OF A ALTIMETRIC GRADIENT UISNG GEOGRAPHIC INFORMATION SYSTEM.}

\begin{abstract}
The present research aimed the characterization of effects of altitude on growth of Palmiteiro (Euterpe edulis). It was defined ten sample plots, systematically distributed with $500 \mathrm{~m}$ intervals, covering all gradient in the mound belongs to formation called Rio das Cobras with $500 \mathrm{~m}$ altitude. For the evaluation of the Palm in the studied area it was cut eight trees in each established level of altitude. The collected data were total biomass and biomass of eatable part. When compared the results it was find tendency between total biomass production and eatable part in relation to altitude gradient. The GIS was construct to find the values of total biomass and eatable part and the tree's density in the area. The GIS will give important information to the forest management.
\end{abstract}

Key-words: GIS, Nutrients, Palms

\section{INTRODUÇÃO}

Segundo Clements (2000) a qualidade do palmito do Euterpe edulis e a destruição acelerada do domínio Floresta Atlântica entre os motivos que mais contribuíram para a quase extinção do palmiteiro. Também, o aumento das famílias das classes sociais média e alta, que são responsáveis por $70 \%$ do consumo de palmito produzido no Brasil. A pressão da produção industrial de palmito, o alto rendimento econômico e a facilidade de exploração da espécie resultaram na instalação de inúmeras indústrias de conserva. Muitas dessas se mantém clandestinas até os dias atuais, e não tendo vínculo com a produção futura, ou sustentabilidade propiciam a devastação das populações naturais de palmiteiro.

Como maior produtor mundial de palmito, respondendo por $85 \%$ do total comercializado no mundo, acredita-se que o Brasil produz cerca de 30.000 toneladas para o mercado externo. Apesar de poucos dados disponíveis, estima-se que a produção no

${ }^{1}$ emer@floresta.ufpr.br, UFPR - Depto. de Ciências Florestais, CEP 80210 - 170, Curitiba PR

2 kirchner@floresta.ufpr.br, UFPR - Depto. de Ciências Florestais, CEP 80210 - 170, Curitiba PR

Recebido para publicação: 10/07/2002

Aceito para publicação 10/03/2003 
mercado interno gire em torno de 40.000 toneladas. Desse total, $42 \%$ são destinadas à cidade de São Paulo, movimentando um montante de 16 milhões de dólares por ano (Cervi, 1996). Pesquisas sobre a biologia e manejo de populações de palmiteiro em florestas naturais ou plantadas são essenciais para a sustentabilidade do palmiteiro, pois ele não se adapta ao modelo agrícola convencional, ou seja, monocultivo a pleno sol, exigindo condições ecológicas específicas, típicas de espécies climáticas, (Clements, 2000).

O palmito é um produto consumido em larga escala e com um ciclo de vida médio de seis anos, Reis et al. (2000). Assim, estudos que contemplem as propriedades nutricionais dos ecossistemas naturais, onde a espécie se desenvolve, tornam-se partes importantes do manejo e da ecologia florestal.

Várias alternativas podem ser utilizadas para garantir um manejo sustentável do palmiteiro, uma delas citadas por Fantini et al. (2000) é a atuação das agências ambientais. A aproximação de organizações não governamentais, universidades e agências ambientais aos pequenos produtores, podem repassar aos pequenos produtores, conhecimentos e formas para garantir a renda a longo prazo. A necessidade de gerenciamento e organização de tamanha gama de dados requer o uso de tecnologias inovadoras para a área florestal. O Sistema de Informação Geográfica (SIG) possui características de inserir e integrar informações espaciais provenientes de mapeamentos, cadastro urbano e rural, dados censitários e de rede em uma única base de dados, possibilitando a manipulação e análise de dados visando a recuperação, consulta, visualização e saída gráfica dos resultados obtidos (Camara; Medeiros, 1996).

O presente trabalho tem como objetivo geral à elaboração de um sistema de informação geográfica para auxiliar na quantificação e avaliação de parâmetros quali-quantitativos do palmiteiro (Euterpe edulis Martius) ao longo de gradientes altimétricos.

Como objetivos específicos, estimarse-á biomassa total dos indivíduos e do creme, e a variação destas ao longo de um gradiente de altitude como também a elaboração de um SIG para a área deste estudo com o intuito de agilizar e facilitar o processo de identificação direta das classes de altitude e suas propriedades, por meio de simples consultas.

Como características gerais do gênero Euterpe, temos 28 espécies que se distribuem ao longo das Antilhas e América do Sul, notadamente nas regiões com Florestas Tropicais. Muitas espécies desse gênero apresentam potencial para a produção de palmito, destacando-se o palmiteiro (Euterpe edulis Martius), com distribuição preferencial ao longo do litoral brasileiro, na Floresta Tropical Atlântica, e o açaizeiro (Euterpe oleracea Martius) no baixo Rio Amazonas (Reitz, 1974).

Klein (1974) caracteriza o palmiteiro como uma espécie esciófila, ou seja, de sombra, ocorrendo dentro de diferentes associações vegetais que the proporcionam sombreamento. Sua maior abundância encontra-se quando associado a florestas que atingiram o seu clímax.

A temperatura média anual das áreas onde ocorrem os palmitos varia entre $17^{\circ} \mathrm{C}$ a $26^{\circ} \mathrm{C}$, sendo a média do mês mais frio de $13^{\circ} \mathrm{C}$ a $24^{\circ} \mathrm{C}$, tolerando regiões com até sete geadas anuais e temperatura média do mês mais quente de $20^{\circ} \mathrm{C}$ a $27^{\circ} \mathrm{C}$ (Carvalho, 1993).

Segundo Carvalho (1993), a espécie ocorre em regiões com precipitação média anual entre $1.000 \mathrm{~mm}$ a $2.200 \mathrm{~mm}$, apresentando melhor crescimento com índices pluviométricos superiores a $1.500 \mathrm{~mm}$, distribuídos de maneira uniforme. A espécie ocorre também em regiões com estacionalidade (Florestas Estacionais), tolerando uma estação seca de até três meses, com déficit hídrico leve, como no sul da Bahia e sul do Mato Grosso do Sul.

Em muitas partes da terra existem barreiras naturais para dispersão de florestas. Em regiões subpolares são as temperaturas frias; em regiões subtropicais pode ser a seca, e em zonas temperadas pode ser as condições extremas do solo tais como salinidade, ou no litoral e em topo de montanhas isoladas podem ser ventos fortes que limitam o avanço da floresta (Tranquillini, 1979).

Variações estacionais como descrito por Kramer e Kozlowski (1972) podem ocasionar uma redução já no inicio do inverno dos processos que são fotossíntese, respiração, metabolismo, etc. Destes processos sintéticos destaca-se a fotossíntese onde são elaborados os 
hidratos de carbono a partir do anidrido carbônico e da água, nos tecidos das plantas contendo clorofila e expostos à luz. É indubitavelmente, o processo fisiológico mais importante que ocorre nas plantas, já que o crescimento depende dos hidratos de carbono que são formados neste processo, ou seja, são substâncias orgânicas básicas a partir das quais são sintetizados todos os outros compostos orgânicos. Também é o ponto de partida para a síntese de gordura e proteínas e são responsáveis por $75 \%$ do peso da matéria seca.

Conforme $o$ autor supracitado, a fotossíntese é um processo que responde a qualquer alteração no meio, como uma mudança na temperatura, intensidade da luminosidade, umidade e fertilidade do solo. Como sendo a principal responsável pelo crescimento dos indivíduos, qualquer alteração nos processos fotossintéticos refletirão inevitavelmente no crescimento das árvores afetando como reflexo a produção de biomassa.

No que se refere a fatores que afetam a produção de biomassa arbórea (Spurr; Barnes, 1982), comentam que a acumulação de biomassa é diferente em cada local onde é medida, refletindo uma variação cuja causa são diversos fatores ambientais e fatores inerentes à própria planta. Existe uma relação entre a biomassa e a produtividade primária, conhecida como relação de acumulação de biomassa. Esta relação geralmente é maior onde a maior parte da energia é utilizada para manter o alto estoque de biomassa existente. Uma das funções de um SIG contempla a espacialização de dados que visa a demonstração e consulta ágil de informações utilizadas para gerenciamento e monitoramento.

De acordo com Souza et al. (1990), a unidade de trabalho maior no SIG é o projeto, o qual corresponde a uma determinada região que pode compreender dados com características diferentes como, por exemplo, a descrição do uso do solo, modelos numéricos do terreno (MNT's).

Um projeto é formado por Planos de Informação (PI's), sendo que um PI reúne todas as informações relacionadas a um certo aspecto do modelo de uma região (Souza et al., 1990). Assim, conforme Formaggio et al. (1992), dentro de um projeto os dados de tipos diferentes, por exemplo, a altimetria, os tipos de solos e os limites de propriedades serão armazenados em PI's distintos.

Para que um SIG possa tratar de informações geográficas de formatos e tipologias distintas, as grandezas geográficas de natureza semelhante serão, agrupadas em uma categoria. Desta forma, grandezas geográficas que possuem propriedades afins pertencerão a uma mesma categoria de dados, os quais segundo Souza et al. (1990) podem se apresentar na forma de áreas.

Para a representação de uma superfície real no computador, é indispensável a elaboração e criação de um modelo digital, que pode estar representado por equações analíticas ou um rede de pontos, de modo a transmitir ao usuário as características espaciais do terreno (INPE, 2000).

Conforme Aronoff (1989) um dos aspectos centrais de um SIG é a possibilidade de geração de mapas contendo informações combinadas sobre a região de interesse. $\mathrm{O}$ modelo define um documento cartográfico como produto a ser gerado pelo sistema, a partir da integração de PI's.

$\mathrm{Na}$ década de 60, os documentos cartográficos disponíveis, não possibilitavam o planejamento prévio das atividades florestais, o que obrigava os técnicos levantarem em campo as informações necessárias para a criação de mapas como os de uso do solo e mesmos assim estes não passavam de apenas um registro (Moreira, 2000).

A variação geográfica do mundo real é infinitamente complexa. Para serem armazenados em um SIG, os dados geográficos precisam estar reduzidos a uma quantidade finita e gerenciável, segundo um conjunto de regras para converter variações geográficas do mundo real em objetos discretos armazenados em meio digital (Ncgia, 1990).

Conforme citado anteriormente, um SIG armazena tanto as definições geográficas das feições da superfície da Terra quanto os atributos ou qualidades que essas feições possuem. A lógica que os diferentes sistemas usam para fazer isto varia bastante, mas quase todos usam uma ou a combinação de dois modelos fundamentais de representação de mapas: vetorial e matricial (Weber, 2001).

No modelo matricial, conforme Weber (2001) a área mapeada é dividida em uma grade 
regular de células com espaçamento conhecido, o que constitui sua resolução espacial. No modelo vetorial as entidades do mundo real são representadas como pontos, linhas ou polígonos. Na verdade a primitiva principal é o ponto, definido como um par de coordenadas $\mathrm{X}$ e Y em um sistema de coordenadas conhecidas (latitude/longitude ou Universal Transverso de Mercator - UTM, etc.). O ponto não possui dimensão, apenas localização. A linha é formada por uma lista de coordenadas de pontos ligados entre si por segmentos de retas. $\mathrm{O}$ polígono define uma superfície bidimensional (área) e é formado por uma cadeia fechada de segmentos de linha (Weber, 2001).

\section{MATERIAL E MÉTODO}

\section{Caracterização da Área de Estudo}

O presente trabalho foi realizado na Fazenda Limeira, município de Guaratuba, região litorânea do Estado do Paraná, localizado entre as coordenadas geográficas $48^{\circ} 46^{\prime} 12^{\prime \prime} \mathrm{W}$ de longitude e $25^{\circ} 42^{\prime} 36^{\prime \prime} \mathrm{S}$ de latitude (fig. 1). A área pertence a Companhia Hemmer Indústria e Comércio Ltda., e abrange 1.162 ha. O presente estudo limitou-se a uma área de 242 ha. Tal fato se deve a procura de um gradiente de altitude que variou de 100 a $500 \mathrm{~m}$ de altitude, limitados a norte, sul e a leste por barreiras naturais (rios), e a oeste pelo limite da propriedade.

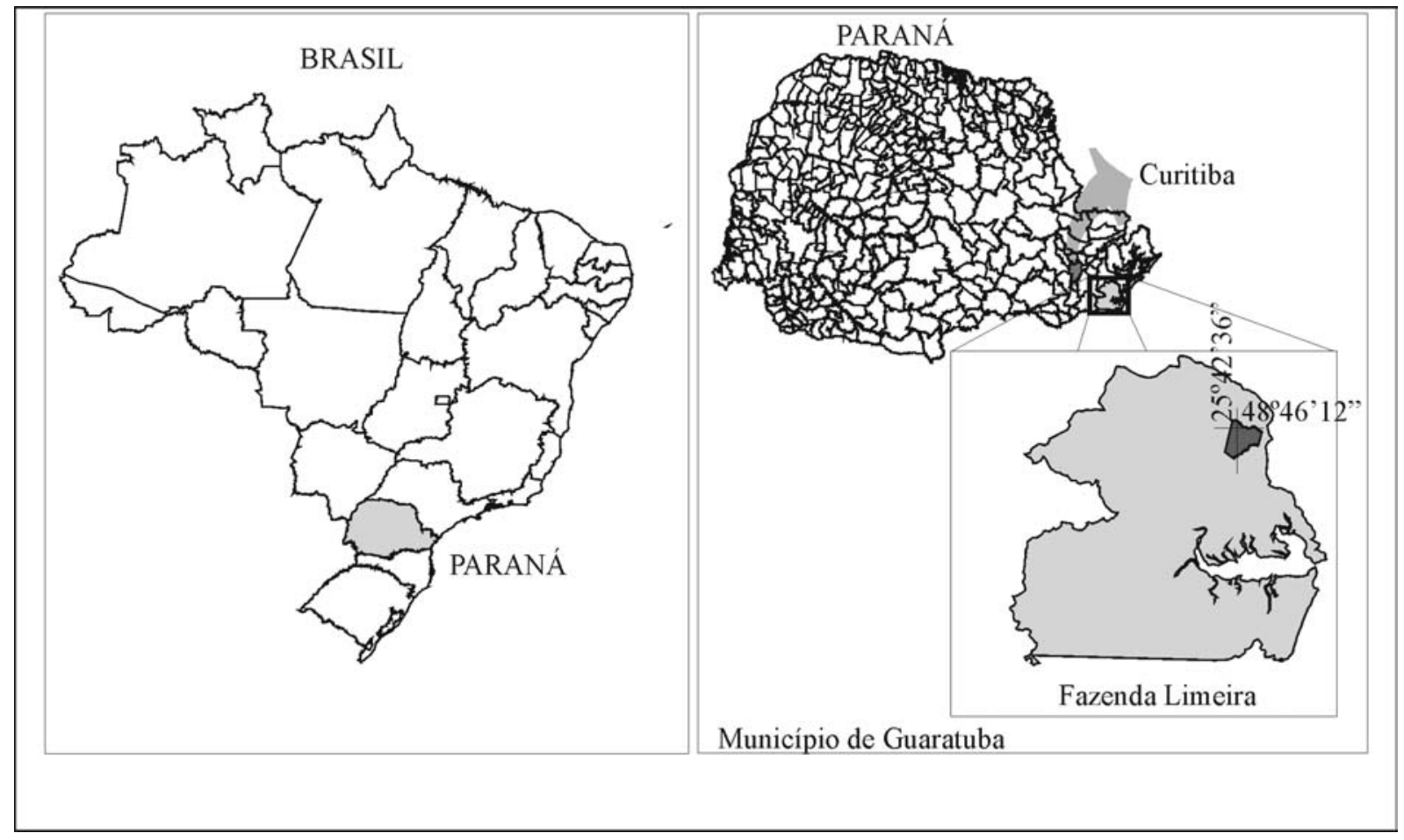

Figura 1: Localização da área de estudo

Figure 1: Localization of studied area

O clima da Serra do Mar no Estado do Paraná e classificada como Cfa pela classificação de Köppen e se caracteriza como um clima chuvoso temperado quente, sempre úmido e com temperatura do mês mais quente superior a $22^{\circ} \mathrm{C}$, com chuvas na maior parte do ano (IAPAR, 1994).

O litoral do Estado do Paraná originada de tensões e zonas de abaixamento da borda leste do continente sul-americano, onde antigos vales de uma paisagem do préterceário ou terceário submergiram no mar, formando as atuais enseadas de ingressão de Paranaguá e Guaratuba (Maack, 1968). No complexo da Serra do Mar, o relevo é bastante acidentado e com áreas íngremes, sendo mais escarpada do lado atlântico do que do lado continental dotada de taludes íngremes $\mathrm{e}$ vertentes vigorosas tanto em relação a zona costeira quanto em relação ao planalto. 
(Bigarella, 1978).

A formação Rio das Cobras, onde está localizada a área de estudo, é formado por uma seqüência xistosa, depósito de vertentes, diques básicos que são constituídos basicamente por muscovita-xistos, biotitaxistos, clorita-xistos, quartzo-xistos, cálcioxistos e subordinadamente, xistos com granada. Os solos predominantes são representados por Cambissolos profundos ou pouco profundos derivados de granitos ou granitóides, e possuem, via de regra, textura argilosa. Os diabásios dão origem com matizes mais avermelhados em relação aos Cambissolos derivados dos granitos. Os xistos dão origem aos Cambissolos e ao Neossolo litólico com textura média ou argilosa UFPR e ITCF (1992). Pela classificação atualizada da Galvão (1999), os solos da Serra do Mar paranaense, são: associação de Cambissolo álico e/ou Argissolos álicos com textura argilosa ou argilosa cascalhenta, Cambissolo álico com A moderado com textura argilosa ou cascalhenta e finalmente por Argissolo vermelho-amarelo álico com A moderado e textura argilosa.

A vegetação predominante na área de estudo é classificada como Floresta Ombrófila Densa Submontana (Roderjan, 1994), que vem sofrendo exploração de palmito desde 1977 até o presente momento. Essa formação florestal se caracteriza por apresentar uma cobertura densa e uniforme, bem desenvolvida, podendo atingir de 25 a $30 \mathrm{~m}$ de altura, compostas em essência por espécies seletivas higrófilas, as quais associam-se outras. O clima tipicamente tropical mostra sua influência no crescimento continuo da vegetação, assim como no interior destas florestas, bastante úmidas e mal ventiladas, ricas em epífitas e com espesso manto de detritos vegetais. Diferentes espécies de palmeiras imprimem feição característica do sub-bosque, notadamente o palmiteiro (Klein, 1984). A fig. 2, mostra a área de ocorrência do palmiteiro no Estado do Paraná, associado às Florestas Ombrófila Densa e Floresta Estacional Semidecidual.

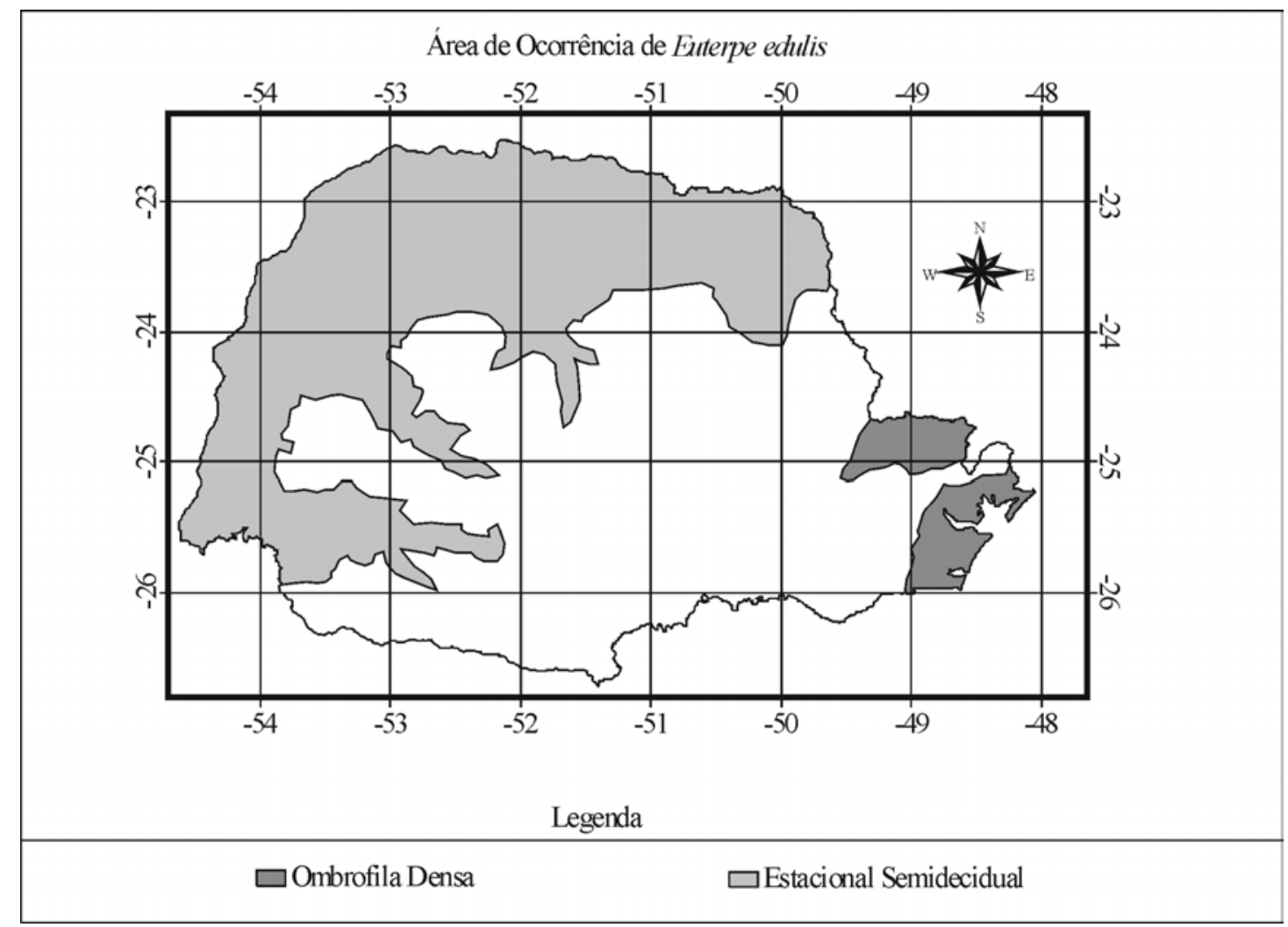

Figura 2: Área de ocorrência do Euterpe edulis

Figure 2: Occurrence area of Euterpe edulis

FONTE: IAPAR, (1994) 
O dossel da Floresta Ombrófila Densa Submontana caracteriza-se pela presença de um grupo heterogêneo de espécies, entre as quais algumas de habitat tropical e que raramente ultrapassam o nível subseqüente das formações montanas (600 a.n.m.), como: Schizolobium parahyba, Pterocarpus violaceus, Aspidosperma olivaceum, Sloanea guianensis, Ficus spp., Centrolobium robustum, Cedrela fissilis, Cabralea canjerana, entre outras. No andar intermediário dessas formações situam-se também espécies características do ambiente tropical como o palmito e a embaúba nas clareiras mais iluminadas. Além destas são comuns o Rheedia spp., Pera glabrata, Gomidesia marlierea, Calyptranthes spp. e Myrceugenia spp., além de outras palmáceas dos gêneros Cocos, Bactris, Attalea, (Veloso, 1957).

\section{Equipamentos Utilizados}

\section{Material Cartográfico}

Para a sistematização e locação das parcelas utilizou-se um mapa planialtimétrico, restituído em 1999 na escala 1:10000 com informações planimétricas (divisas, hidrografia, edificações e estradas) e altimétricas (pontos cotados, curvas mestras com eqüidistância de $50 \mathrm{~m}$ e intermediárias de $10 \mathrm{~m})$, o qual forneceu subsídios para a elaboração do mapa relativo ao MNT (modelo numérico do terreno).

\section{Programas Computacionais}

Para gerenciar todo o conjunto de atributos gráficos e alfanuméricos, utilizou-se o software ArcView GIS 3.2 por sua boa comunicação com softwares do tipo "CAD" (AutoCad) e drives de banco de dados, como por exemplo "ODBC", assim como sua interface amigável e a facilidade de realização de consultas que é essencial em software de SIG. Os dados coletados em campo foram analisados utilizando-se o pacote estatístico MSTAT-C, versão 2.11.

Localização das Amostras em Campo

Para a instalação adequada dos pontos amostrais em campo, foi necessário utilizar os seguintes aparelhos: GPS (Global Positioning System) modelo Garmin II Plus, instrumento que fornece a localização por coordenadas geográficas, uma bússola e um altímetro.

\section{Coleta de Dados no Campo}

A coleta de dados ocorreu em duas etapas distintas, a primeira de levantamento de dados do palmiteiro e a segunda de coleta de solos da área de estudo.

Levantamento de dados do Palmiteiro

Esta etapa ocorreu em julho/2001, onde foram levantadas 10 parcelas de $10 \times 100$ $\mathrm{m} \quad\left(1000 \mathrm{~m}^{2}\right)$, distribuídas de forma sistemática, eqüidistante $500 \mathrm{~m}$, sendo que a primeira parcela foi locada de forma aleatória (fig. 3).

Para definição dos pontos amostrais levou-se em consideração a intercessão das linhas de grade, definindo-se duas unidades amostrais por intervalo altimétrico conforme apresentado no quadro 1. Para locação das unidades amostrais, utilizou-se coordenadas UTM, extraídas do mapa e locadas em campo através do GPS.

Quadro1: Definição das classes de níveis altimétricos

Chart 1: Definition of altimetric levels classes

\begin{tabular}{|c|c|}
\hline Nível Altimétrico & Altitude (m) \\
\hline 1 & $100-150$ \\
\hline 2 & $150-200$ \\
\hline 3 & $200-250$ \\
\hline 4 & $250-350$ \\
\hline 5 & $350-450$ \\
\hline
\end{tabular}

A configuração da área amostrada, visualizado na fig. 3, é demonstrado por um perfil elaborado no software ArcView 3.2 GIS, e pode ser visualizado na fig. 4. 


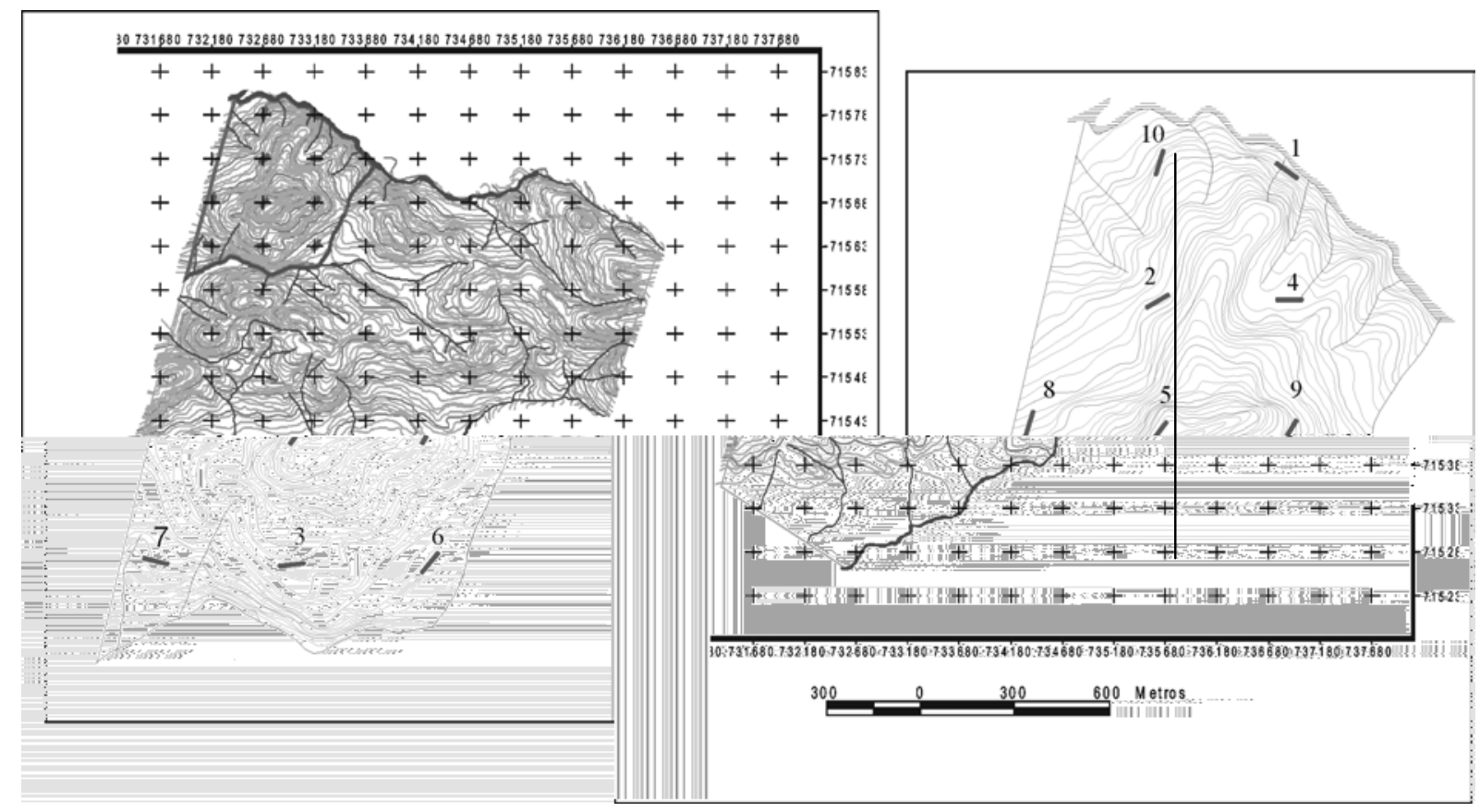

Figura 3: Sistema de distribuição das unidades amostrais na área de estudo Figure 3: System of sample plots unit distribution in the studied area

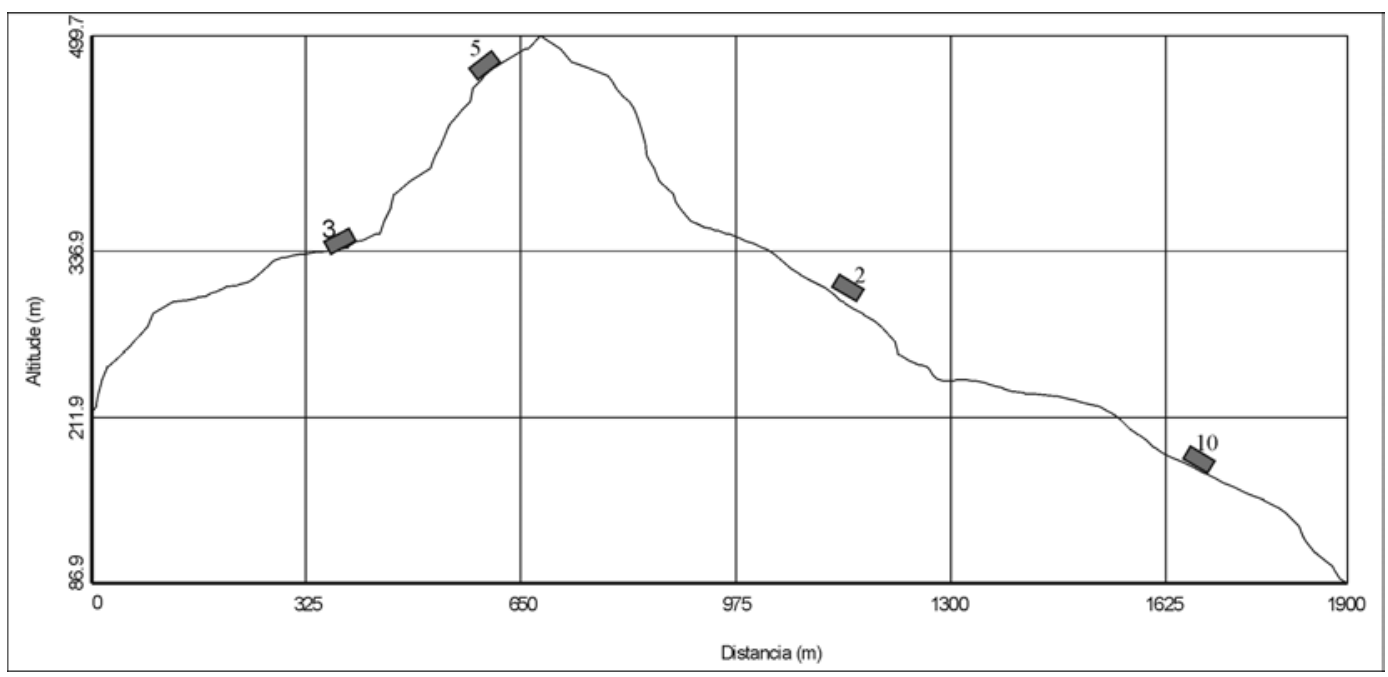

Figura 4: Perfil das unidades amostrais da seqüência central, apresentada na fig. 3

Figure 4: Cross section of central sequence sample plots showed in fig. 3

A suficiência amostral foi definida a partir de um levantamento anteriormente realizado pela própria empresa, através do qual foi possível dimensionar o número de 10 parcelas (erro amostral de 10\%) através da seguinte expressão demonstrada por Péllico (1997):

$\mathrm{n}=\frac{\mathrm{t}^{2} \mathrm{~s}^{2}}{\mathrm{E}^{2}+\frac{t^{2} s^{2}}{N}}$ Onde: $E=L E * \bar{x} ;$

$$
s^{2}=\frac{\sum x^{2}-\frac{\left(\sum x\right)^{2}}{n}}{n-1} \text {, onde: } n \text { - numero de }
$$

amostras; $t$ - valor tabelado; $E$ - erro amostral; $L E$ - limite do erro(10\%); $\bar{x}$ - média estimada de ind./ha; $s^{2}-$ variância ( $\mathrm{n}^{\mathrm{o}}$ ind./ha).

Em cada parcela mediu-se todos os palmiteiros com altura total $\geq 1,5 \mathrm{~m}$. Visando fornecer subsídios para a análise da qualidade do creme do palmiteiro registrou-se, para todos os indivíduos:

- CAP $(\mathrm{cm})$ - é o diâmetro do indivíduo 
medido a $1.3 \mathrm{~m}$, a partir do solo;

- Altura total (m) - medida ao nível do solo até a inserção da última folha;

- Altura da estipe (m) - medida ao nível do solo até o início do gomo ou ocre;
Em cada parcela foram abatidos quatro indivíduos de palmiteiro, representativo de cada classe diamétrica, seguindo a resolução 031/98/SEMA - PR, que define as classes de qualidade do creme (quadro 2).

Quadro 2: Classes de diâmetro do creme

Chart 2: Diameter class of cream

\begin{tabular}{|c|c|}
\hline Classe de Qualidade do Creme & Diâmetro do Creme (cm) \\
\hline Primeira (I) & $\geq 4$ \\
\hline Segunda (II) & $3,0-3,99$ \\
\hline Terceira (III) & $2,5-2,99$ \\
\hline Quarta (IV) & $\leq 2,49$ \\
\hline
\end{tabular}

FONTE: Reis, 2000

Para a obtenção biomassa total aérea dos indivíduos foram selecionados os quatros primeiros indivíduos da parcela, localizados na face norte, sendo um de cada classe de diâmetro do palmito. Após o indivíduo ser abatido e ainda fresco, foi dividido nas seguintes partes: parte aérea (folhas, raques e bainha), Cabeça (palmito) e a estipe, e posteriormente pesados (fig. 5).

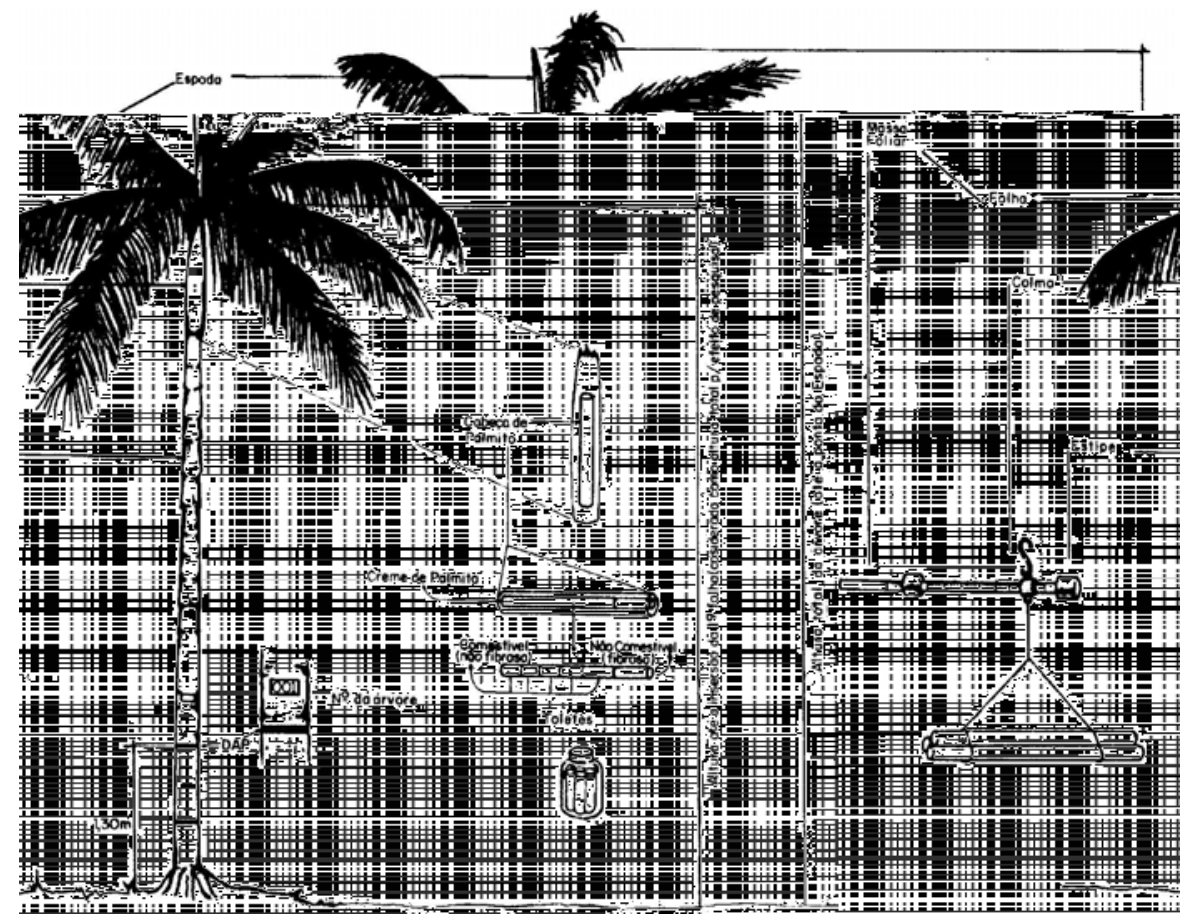

Figura 5: Subdivisão do Euterpe edulis Martius, para a obtenção da biomassa

Figure 5: Subdivision of Euterpe edulis Martius, for obtaining the biomass

FONTE: Wendling (1998)

Foram retiradas três amostras da estipe, em forma de disco com aproximadamente $15 \mathrm{~cm}$ de espessura, sendo uma na base outro na parte mediana e finalmente próximo a cabeça do palmito, estas amostras foram colocadas em estufa e secas, para o calculo da biomassa total do palmiteiro.
A fase subseqüente compreendeu $\mathrm{o}$ processamento da cabeça para a separação do palmito. Foram retiradas duas amostras de classe de diâmetro do palmito por nível altimétrico para a análise nutricional. Para a obtenção da estimativa da biomassa do palmito, foram obtidos os pesos frescos e 
posteriormente o peso seco.

\section{Análises Estatísticas}

\section{Análise de variância}

Os dados referentes aos níveis de macro e micro nutrientes, bem como os referentes à biomassa total seca e peso total do creme seco, foram submetidos a análise de variância, segundo um delineamento inteiramente casualizado, com 20 tratamentos e duas repetições. Os tratamentos representam o arranjo fatorial de 5 níveis de altitude (A) e 4 classes de diâmetro de creme (C), conforme apresentado na quadro 3 .

As variâncias dos tratamentos foram testadas quanto a sua homogeneidade pelo teste de Barttlet, segundo Steel e Torrie (1960). A comparação de médias entre os níveis altimétricos, classes de diâmetro e as interações foi realizada através do Teste de Tukey.

Quadro 3: Arranjo fatorial de 4 classes de diâmetro e 5 níveis de altitude

Chart 3: Factorial arrange of 4 diameter classes and 5 altitude levels

\begin{tabular}{|c|c|c|}
\hline Tratamento & Classe de Diâmetro $(\mathrm{cm})$ & Níveis Altimétricos (m) \\
\hline $01 \quad \mathrm{C}_{1} \mathrm{~A}_{1}$ & $>4,5$ & A1 $100-150$ \\
\hline $02 \quad \mathrm{C}_{1} \mathrm{~A}_{2}$ & $>4,5$ & $151-200$ \\
\hline $03 \quad \mathrm{C}_{1} \mathrm{~A}_{3}$ & $>4,5$ & $201-250$ \\
\hline $04 \quad \mathrm{C}_{1} \mathrm{~A}_{4}$ & $>4,5$ & $251-350$ \\
\hline $\mathrm{C}_{1} \mathrm{~A}_{5}$ & $>4,5$ & $351-450$ \\
\hline $\begin{array}{ll}06 & \mathrm{C}_{2} \mathrm{~A}_{1} \\
\end{array}$ & $3,5-4,4$ & $100-150$ \\
\hline $07 \quad \mathrm{C}_{2} \mathrm{~A}_{2}$ & $3,5-4,4$ & $151-200$ \\
\hline $08 \quad \mathrm{C}_{2} \mathrm{~A}_{3}$ & $3,5-4,4$ & $201-250$ \\
\hline $09 \quad \mathrm{C}_{2} \mathrm{~A}_{4}$ & $3,5-4,4$ & $251-350$ \\
\hline $10 \quad \mathrm{C}_{2} \mathrm{~A}_{5}$ & $3,5-4,4$ & $351-450$ \\
\hline $11 \quad \mathrm{C}_{3} \mathrm{~A}_{1}$ & $2,9-3,4$ & $100-150$ \\
\hline $12 \quad \mathrm{C}_{3} \mathrm{~A}_{2}$ & $2,9-3,4$ & $151-200$ \\
\hline $13 \quad \mathrm{C}_{3} \mathrm{~A}_{3}$ & $2,9-3,4$ & $201-250$ \\
\hline $14 \quad \mathrm{C}_{3} \mathrm{~A}_{4}$ & $2,9-3,4$ & $251-350$ \\
\hline $15 \quad \mathrm{C}_{3} \mathrm{~A}_{5}$ & $2,9-3,4$ & $351-450$ \\
\hline $\mathrm{C}_{4} \mathrm{~A}_{1}$ & $<2,9$ & $100-150$ \\
\hline $17 \quad \mathrm{C}_{4} \mathrm{~A}_{2}$ & $<2,9$ & $151-200$ \\
\hline $18 \quad \mathrm{C}_{4} \mathrm{~A}_{3}$ & $<2,9$ & $201-250$ \\
\hline $19 \quad \mathrm{C}_{4} \mathrm{~A}_{4}$ & $<2,9$ & $251-350$ \\
\hline $20 \quad \mathrm{C}_{4} \mathrm{~A}_{5}$ & $<2,9$ & $351-450$ \\
\hline
\end{tabular}

\section{Elaboração de um Sistema de Informação Geográfica}

\section{Metodologia de construção do SIG}

Para assegurar a qualidade das informações geradas, tornou-se necessário uma edição final da base cartográfica, através de uma varredura automática de elementos lineares para identificar possíveis erros de representação gráfica, o que poderia acarretar erros geométricos, que também são chamados de erros topológicos. A edição final serviu também para inserir os valores das isolinhas à base cartográfica, imprescindíveis para a construção do modelo tri-dimensional da área de estudo (MNT).

Buscou-se apresentar no mapa de MNT as delimitações de cada nível altimétrico, tratado aqui como unidades de produção
(U.P.), termo utilizado por Drago (1999). As UPs foram implementadas com os dados oriundos do levantamento de campo e as entradas dos dados receberam atenção especial, pois é nesta fase que podem ocorrer erros que comprometam o sistema como um todo (Kirchner, 1994).

Através do MNT pôde-se criar os dados gráficos (polígonos) que são utilizados como as entidades físicas e que estão associados aos níveis altimétricos, bem como os dados não gráficos, que são formados pelos dados alfanuméricos, e que se relacionam com cada entidade física de interesse (UP).

Os dados alfanuméricos, provenientes do levantamento de campo e das análises estatísticas foram incorporados em um banco de dados relacional do Access e posteriormente incorporados ao ArcView GIS 
3.2. Definiu-se então as categorias das tabelas, onde foram inseridos os dados do tipo (DAP, Altura, densidade absoluta e biomassa total), conforme apresentado na fig. 6 .

Foram elaboradas 6 tabelas, das quais cinco continham dados gerais do levantamento de campo, onde as unidades amostrais foram agrupadas por nível altimétrico e uma outra tabela referente aos dados gráficos na qual continha os valores dos níveis altimétricos, e que pode, segundo Healey (1993) ser considerada "pais" ou registros principais. Os registros principais foram associados, por chaves ou índices, aos vários filhos, que neste caso são as unidades amostrais agrupadas em níveis altimétricos. Estas operações com o banco de dados foram realizadas em função da ocorrência de vários registros de CAP, altura, densidade e classe de diâmetro para um único polígono.

Para a importação dos dados das tabelas agrupadas por níveis altimétricos no
Microsoft Access para o ArcView, utilizou-se o comando "SQL conect".

As relações utilizadas para associar as tabelas foram do tipo "um-para-vários" como metodologia utilizada por Drago (1999). A chave de ligação utilizada para espacializar as informações obtidas em campo com a base cartográfica foi definida por um campo em comum, que neste caso foi "elevation". Através do comando "join" foi espacializado os valores médios de CAP, altura, densidade e biomassa total, obtendo-se todos os dados referenciados correspondente a cada nível altimétrico (fig. 7).

\section{RESULTADOS}

\section{Biomassa Total e do Creme}

Os valores encontrados para a biomassa total e do creme (quadro 4) foram submetidos a uma análise de variância.

Quadro 4: Biomassa total e do creme em função da classe de diâmetro e dos níveis altimétricos

Chart 4: Total and cream biomass according to diameter class and altimetric levels

\begin{tabular}{|c|c|c|c|}
\hline Classe de Diâmetro & Níveis Altimétricos (m) & Biomassa Total (Kg) & Biomassa do Creme(Kg) \\
\hline C14 & $100-150$ & 47,1 & 0,040 \\
\hline C1 & $151-200$ & 49,9 & 0,075 \\
\hline C1 & $201-250$ & 32,7 & 0,065 \\
\hline C1 & $251-350$ & 40,9 & 0,045 \\
\hline C2 & $351-450$ & 24,0 & 0,035 \\
\hline C2 & $100-150$ & 19,1 & 0,035 \\
\hline C2 & $151-200$ & 27,0 & 0,045 \\
\hline C2 $201-250$ & 29,1 & 0,055 \\
\hline C3 & $201-30,2$ & 0,025 \\
\hline C3 & $251-350$ & 15,6 & 0,020 \\
\hline C3 & $351-450$ & 10,1 & 0,010 \\
\hline C3 & $100-150$ & 13,8 & 0,020 \\
\hline C3 & $151-200$ & 12,5 & 0,020 \\
\hline C4 & $201-250$ & 9,1 & 0,015 \\
\hline C4 & $251-350$ & 8,8 & 0,020 \\
\hline C4 & $351-450$ & 5,7 & 0,005 \\
\hline C4 & $100-150$ & 6,2 & 0,010 \\
\hline
\end{tabular}

Estes variáveis apresentam uma diferença significativa entre as classes de diâmetro ao nível de $5 \%$ de probabilidade, não apresentando diferenças significativas para os níveis altimétricos. O teste de Tukey (tab. 1) mostrou que a classe de diâmetro maior do que $4,5 \mathrm{~cm}$ foi estatisticamente superior as demais para a biomassa total e que não existe diferença estatística significativa entre as classes de diâmetro maiores do que $3,4 \mathrm{~cm}$ para a biomassa do creme. A maior média encontrada para a biomassa total $(151-200$ m) foi 6,8 vezes maior do que a menor (351$450 \mathrm{~m}$ ), enquanto que para a biomassa do creme esta diferença foi de 4,7 vezes. 
Tabela 1: Biomassa total e do creme do palmiteiro em função da classe de diâmetro

Table 1: Total and cream biomass of palmiteiro according to diameter class

\begin{tabular}{lll}
\hline \multicolumn{1}{c}{ Classe de diâmetro do Palmito } & $*$ PTCS kg & $* *$ BTSECA kg \\
\hline$>4,5 \mathrm{~cm}$ & $0.052 \mathrm{a}$ & $38.935 \mathrm{a}$ \\
$3,5-4,4 \mathrm{~cm}$ & $0.036 \mathrm{ab}$ & $22.214 \mathrm{~b}$ \\
$2,9-3,4 \mathrm{~cm}$ & $0.017 \mathrm{bc}$ & $10.883 \mathrm{c}$ \\
$<2,9 \mathrm{~cm}$ & $0.011 \mathrm{c}$ & $5.744 \mathrm{c}$ \\
\hline
\end{tabular}

Médias seguidas pela mesma letra minúscula não diferem pelo teste de Tukey ao nível de 5\% de probabilidade NOTAS: * biomassa do creme

** biomassa total

Apesar de não terem sido verificadas diferenças estatísticas dentro dos níveis de altitude para a biomassa total e do creme, é possível verificar a existência de uma variação nos resultados (tab.2). A biomassa total (tab. 1, no item resultados) quando correlacionada aos níveis altimétricos apresentou uma correlação forte e positiva (fig. 6). Esta correlação indica uma tendência da biomassa total, variar em relação ao gradiente altimétrico, neste caso tendo uma redução na produção nos níveis altimétricos mais altos $(251-350 \mathrm{~m}$ e $351-$ $450 \mathrm{~m})$.

As diferenças detectadas do nível que produziu maior biomassa total $(151-200 \mathrm{~m}) \mathrm{e}$ o que produziu a menor biomassa total (351 $450 \mathrm{~m}$ ) foi da ordem de 44,6\% (tab.2).

Tabela 2: Média da biomassa total e do creme nos diferentes níveis altimétricos

Table 2: Average of total and cream biomass in the different altimetric levels

\begin{tabular}{ccc}
\hline Níveis Altimétricos & BTSECA kg & PTSC g \\
\hline $100-150 \mathrm{~m}$ & 20,516 & 22,00 \\
$151-200 \mathrm{~m}$ & 24,244 & 37,00 \\
$201-250 \mathrm{~m}$ & 20,731 & 37,00 \\
$251-350 \mathrm{~m}$ & 18,306 & 25,00 \\
$351-500 \mathrm{~m}$ & 13,422 & 22,00 \\
\hline
\end{tabular}

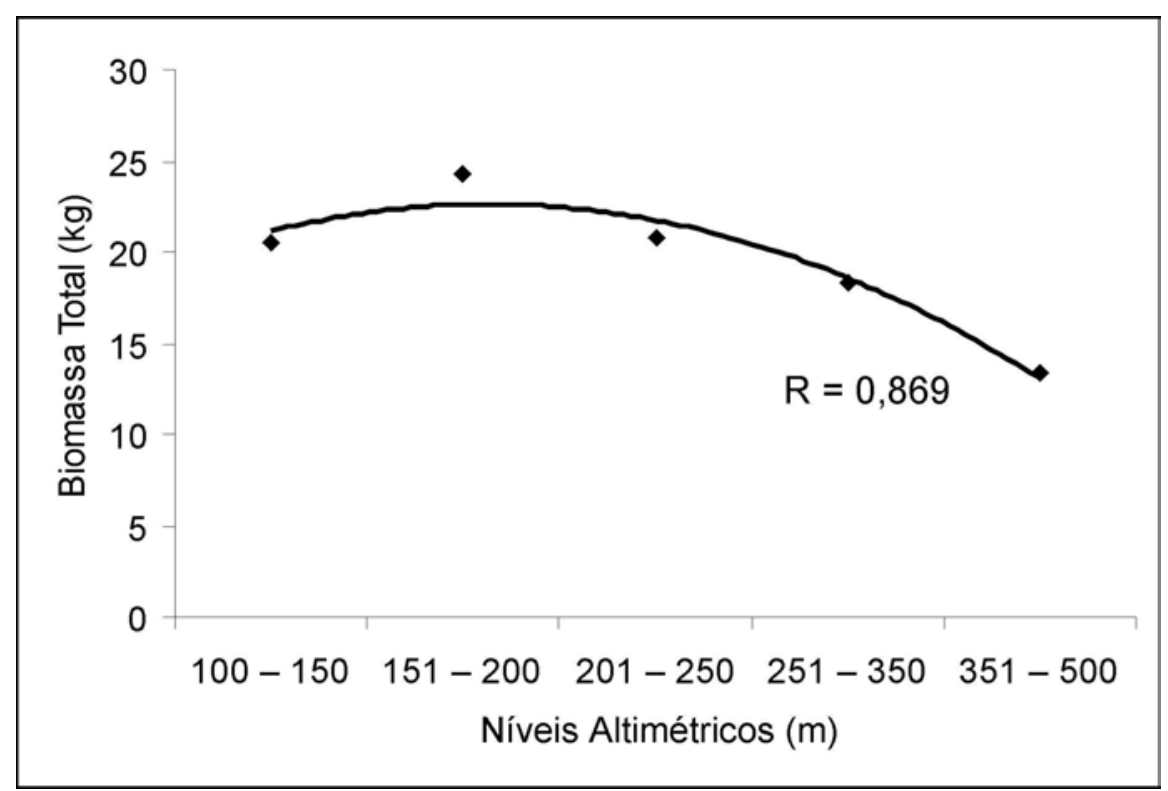

Figura 6: Relação entre a biomassa total do palmiteiro no gradiente de altitude

Figure 6: Relation between total biomass of palmiteiro in altitude gradient 
Como também é apresentada na tabela 5, a biomassa do creme apresentou uma correlação com os níveis altimétricos $(0,55)$, porém neste caso uma correlação fraca (fig. 7). Esta correlação indica que a biomassa do creme é influenciada pela altitude, em menor proporção do que a biomassa total do palmiteiro, ou seja, também há uma redução na produção de creme do palmiteiro nos níveis altimétricos superiores $(251-350 \mathrm{~m}$ e $351-$ $450 \mathrm{~m}$ ), porém menos sensíveis.

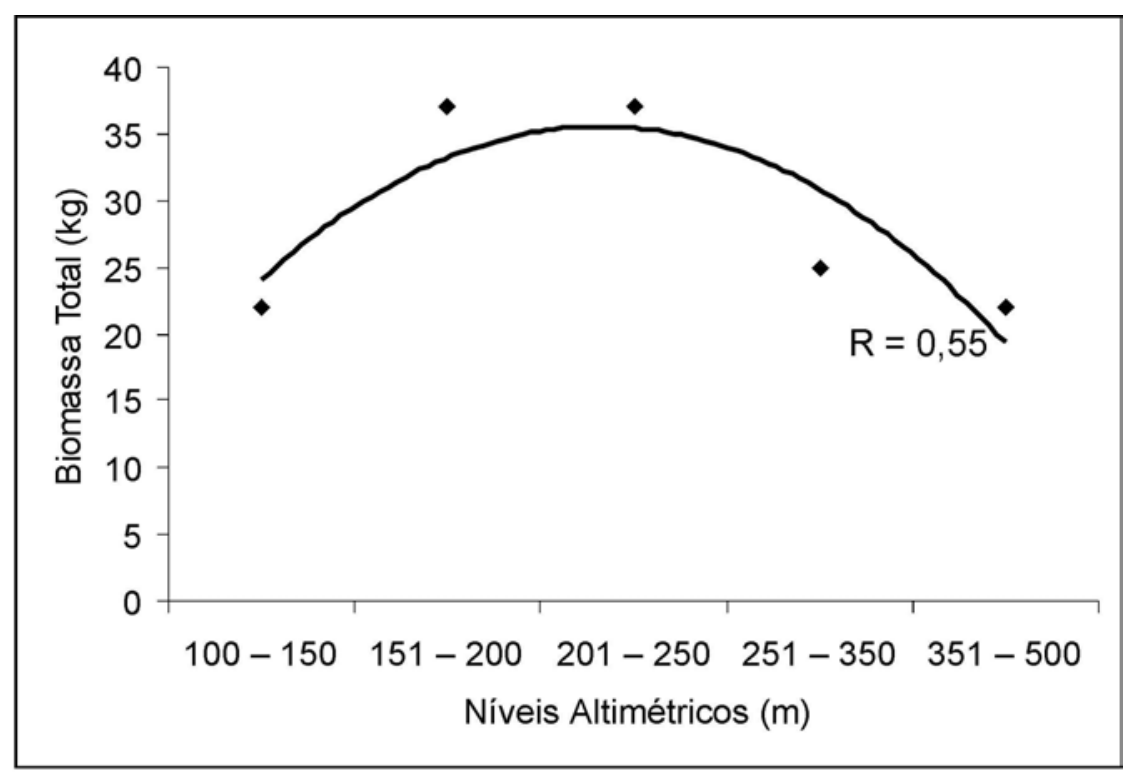

Figura 7: Relação entre a biomassa total do creme no gradiente de altitude Figure 7: Relation between total cream biomass in altitude gradient

\section{Sistema de Informação Geográfica}

Com a construção do modelo numérico do terreno (MNT) (fig. 8) e a importação dos dados alfanuméricos para o "Arc View", obtidos através das etapas de aquisição de dados de campo e laboratório foi possível proceder operações de consultas, as quais subsidiam ações ao planejamento florestal obtidas através do gerenciamento adequado de dados em ambiente SIG.

O gerenciamento dos dados em um SIG pode partir mediante consultas, através de identificação direta das entidades ou de localização de feições através de expressões matemáticas, obter resumos estatísticos e análises topológicas. O SIG permite ainda realizar infinitas possibilidades de cruzamento de dados através de operações lógicas (Drago, 1999), desta forma buscou-se realizar alguns exemplos das consultas que podem ser realizadas e que poderão auxiliar na tomada de decisão.

Existem várias maneiras de executar consultas em um SIG, sendo que as mais simples são obtidas através de identificação visual com o auxilio das ferramentas "identify" ou "select feacture". Esta ferramenta tem associação direta do dado gráfico com 0 alfanumérico. Outra forma simples de se identificar feições é através do comando "find" que permite localizar por palavra um elemento gráfico.

Para questões mais complexas pode-se realizar as consultas através do "Query Built", onde é possível utilizar expressões matemáticas. Nestas operações também podem ser utilizados operadores "booleanos" como "and, or, not" e também operações como adição, multiplicação, potência dentre inúmeras outras.

Para demonstrar um exemplo prático destes operadores acima citados, formulou-se a seguinte questão hipotética: "quais níveis altimétricos possuem uma densidade de indivíduos superior a 500 ind./ha?" (figura 9). Outras questões podem ser formuladas, como por exemplo, quais níveis altimétrico 
possuíram a média da biomassa total dos indivíduos superior a 20,6 kg? As respostas foram os níveis altimétricos 151 - 200 m e 201 $-250 \mathrm{~m}$ (fig. 10).

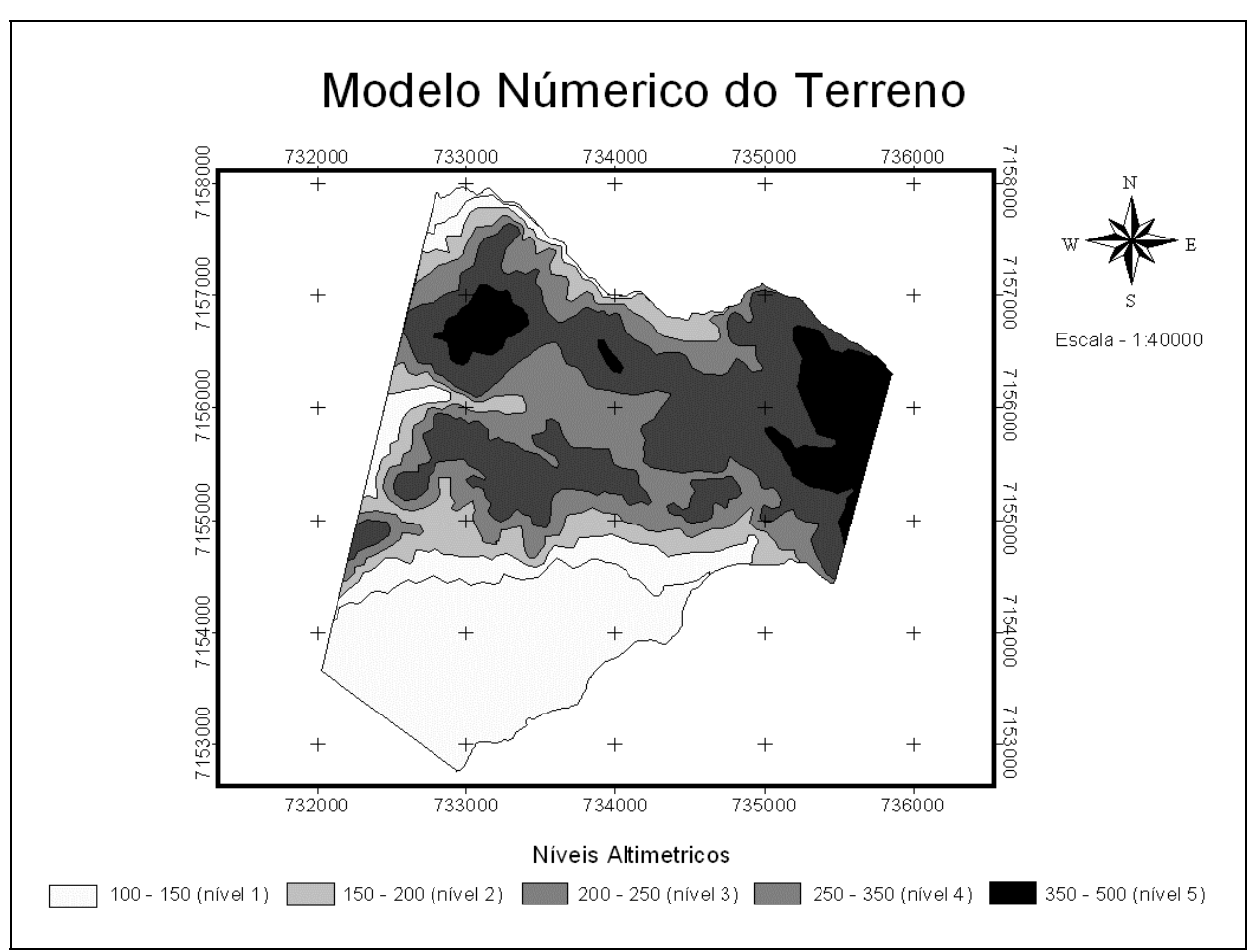

Figura 8: Mapa do modelo numérico do terreno

Figure 8: Map of ground numeric model

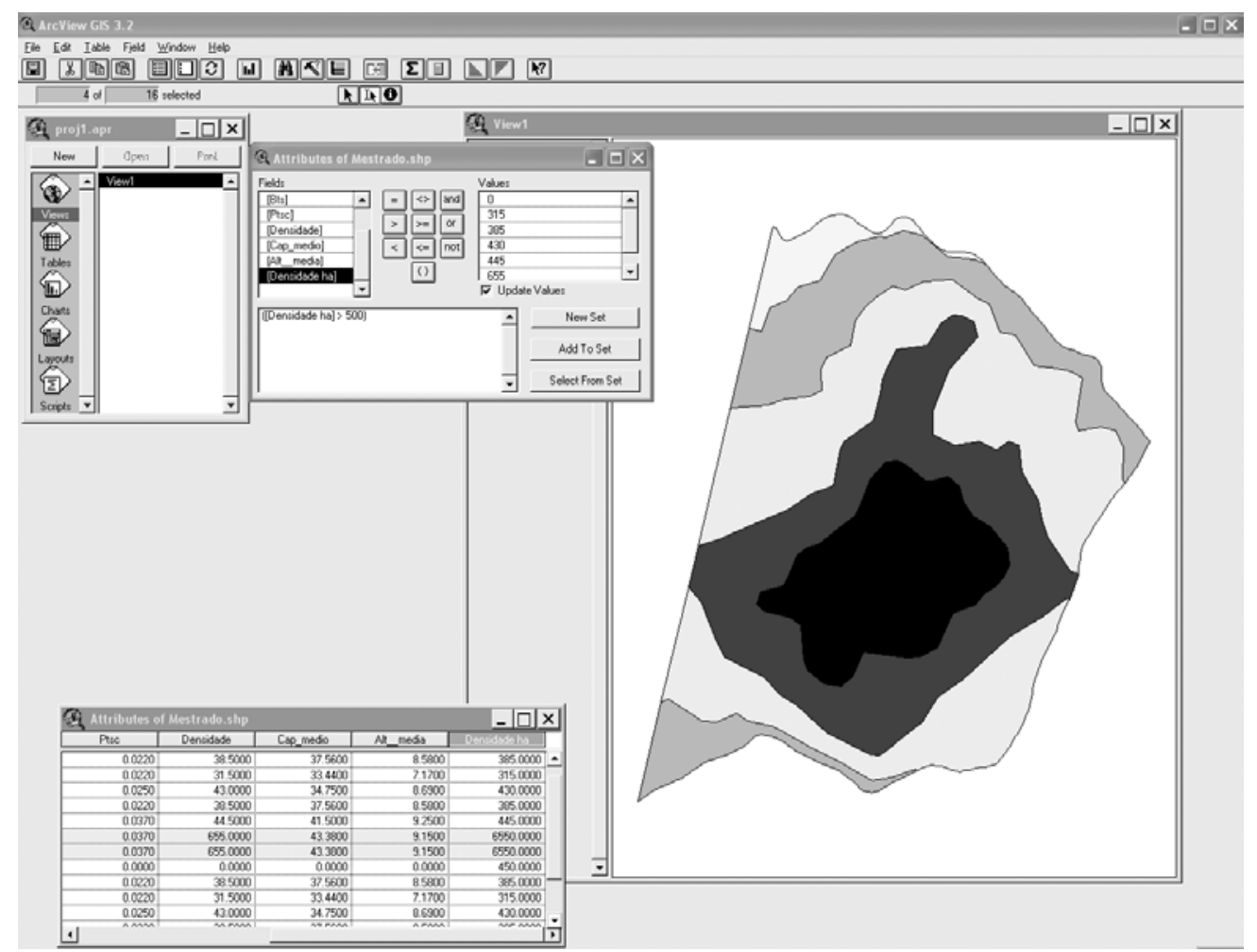

Figura 9: Utilização do comando "query built", para consultar a densidade de indivíduos, por nível altimétrico Figure 9: Check of plants density in an altimetric level by using "query built" command 


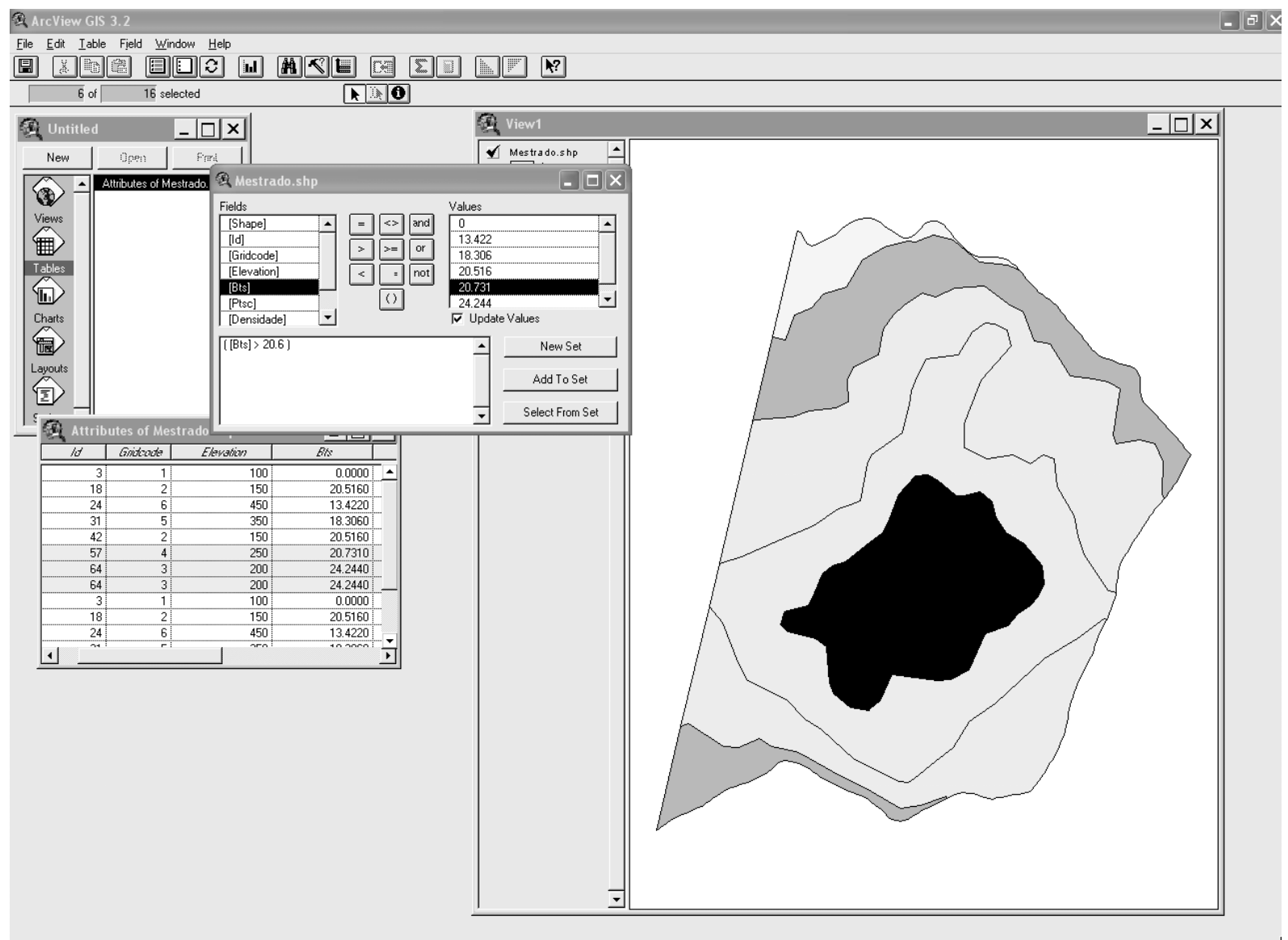

Figura 10: Utilização do comando "query built", para consultar a média da biomassa total, por nível altimétrico Figure 10: Check of average total biomass in an altimetric level by using "query built” command

\section{CONCLUSÕES}

Tendo como elementos balizadores os resultados obtidos, a metodologia empregada nesta pesquisa atendeu aos objetivos previamente estabelecidos, sendo importante destacar os seguintes aspectos conclusivos:

- Não foi evidenciada diferença estatística dentre os níveis altimétricos estudados em relação ao peso total do creme e biomassa total do indivíduo, porém percebe-se uma tendência da diminuição dessas variáveis com o aumento da altitude;

- A correlação entre a biomassa total e os níveis altimétricos apresentaram-se altas, enquanto que para a biomassa do creme foi encontrada uma correlação moderada.

- .Um Sistema de Informação Geográfica permitiu agilizar e facilitar o processo de identificação direta das entidades topológicas, necessárias neste caso por se tratar de uma floresta nativa, e necessitarmos de uma unidade de avaliação, com um talhão, por exemplo, para este estudo. A identificação das características das feições, das unidades de avaliação, através de simples consultas, subsidia as ações ligadas ao planejamento florestal, que podem ser utilizadas em amplas funções, como nas operações de manejo florestal, de planejamento e execuções em campo.

\section{REFERÊNCIAS}

ALVES, D. S. Sistemas de Informações Geográficas. In: SIMPÓSIO BRASILEIRO DE GEOPROCESSAMENTO, 1. Anais... São Paulo: Escola Politécnica/USP. 1990. p. 66-78.

ARONOFF, S. Geographic information systems: a management perspective. Ottawa: WDL. 1989. 295 p.

Bigarella, J. J. A Serra do Mar e a Porção Oriental do Estado do Paraná. Curitiba: ADEA. 1978. 249p. 
BURROUGH, P. A. Principles of geographical information systems for earth resources assessment. Oxford: Clarendon, 1986. 193p.

CÂMARA, G., MEDEIROS, J. S. Geoprocessamento para projetos ambientais. São José dos Campos: INPE, 1996. $123 \mathrm{p}$.

CARVALHO, P. E. Silvicultura de espécies nativas do Brasil. Curitiba: EMBRAPA, 1993. $705 \mathrm{p}$.

CERVI, C. E. O mercado de palmito: relatório para o Conselho Britânico. Local: Itajaí, 1996. 34p.

CLEMENTS C. R. Manejo sustentável do Palmiteiro. In: Reis M. S.; REIS, A. Euterpe edulis Martius (palmiteiro): biologia, conservação e manejo. Itajaí: Herbário Barbosa Rodrigues,. 2000.

COLGALTON, R. G.; GREEN, K. The ABC's of GIS: an introduction to geographic information systems. Journal of Forestry, Washington, D.C., v. 90, n. 11, p. 13-20, 1992.

DRAGO, D. A Elaboração de um sistema de informação geográfica (SIG) para a Estação Experimental de Rio Negro da UFPR. CURITIBA, 1999. 127f. Dissertação (Mestrado em Ciências Florestais) - Setor de Ciências Agrárias, Universidade Federal do Paraná.

EMBRAPA. Sistema brasileiro de classificação de solos. Brasília, 1999. 412p.

FANTINI, A. C.; RIBEIRO, R. J.; GURIES R. P. Manejo sustentável do Palmiteiro. In: Reis M. S.; REIS, A. Euterpe edulis Martius (palmiteiro): biologia, conservação e manejo. Herbário Barbosa Rodrigues, Itajaí, 2000. p. 256-280.

FORMAGGIO, A . R.; ALVES, D. S.; EPIPHANIO, J. C. N. Sistemas de informação geográfica na obtenção de mapas de aptidão agrícola e de taxa de adequação de uso das terras. Revista Brasileira da Ciência do Solo, Campinas, n. 16, p. 249-256, 1992.

GALVÃO L. S. Instituto Nacional de Pesquisas Espaciais - INPE, Divisão de Sensoriamento Remoto. Comportamento Espectral dos Alvos. Disponível em: http://www.ltid.inpe.br/dsr/dsr/grupos/espec tral. Acesso em 22 Jan. 2002.

HEALEY, R. G. Database management systems. In: MAGUIRE, D. J., GOODCHILD, M. F., RHIND, D. W. Geographical information system. New York: Longman Scientific \& Technical. 1993. p $251-265$.

IAPAR. Cartas Climáticas do Estado do Paraná. Londrina: 1994. 49p.(Documento 18).

KIRCHNER, F. F.; PREOSCK, R. E.; DESTRO J. N. Implementação de um GIS. SEMINÁRIO DE ATUALIZAÇÃO EM SENSORIAMENTO REMOTO E SISTEMAS DE INFORMAÇÕES GEOGRÁFICAS APLICADAS À ENGENHARIA FLORESTAL. 1. Anais... Curitiba: FUPEF. 1994.

KLEIN, R. M. Euterpe edulis Martius observações ecológicas. In: REITZ, R. (Ed.). Palmeiras., Itajaí: Flora Ilustrada Catarinense. 1974. p. 102-105.

KRAMER, P. J., KOZLOWSKI, T. T. Fisiologia das árvores. Lisboa: Fundação Kalouste Goulbenkian. 1972. 745 p.

LACHOWSKY, H. MAUS, P.; PLATT, B. Integrating remote sensing with GIS. Journal of Forestry, Washington, D.C.: v. 90, n. 12, p. 16-21, 1992.

MAACK, R. Geografia física do Estado do Paraná. Curitiba: Banco de Desenvolvimento do Paraná/Universidade Federal do Paraná,1968. 329p.

MOREIRA, C. A.; LUNARDI, O. A; RIBAS JUNIOR, U. Implantação do Sistema de Informações Geográficas para a Divisão Florestal da Empresa Battistella (Mobasa). In: SEMINÁRIO DE ATUALIZAÇÃO EM SENSORIAMENTO REMOTO E SISTEMAS DE INFORMAÇÕES GEOGRÁFICAS APLICADAS À ENGENHARIA FLORESTAL, 4. Anais... Curitiba: Editorado por: Atilio Disperatti e Nelson Carlos Rosot. 2000. 186 p.

PÉLLICO NETTO, S; BRENA D. A. Inventário Florestal. Curitiba: 1997. 316 p.

REIS, M. S. et al. Manejo sustentável do Palmiteiro. In: REIS, M. S.; REIS, A. Euterpe edulis Martius (palmiteiro): biologia, 
conservação e manejo. Herbário Barbosa Rodrigues, Itajaí: 2000b. p. 202-224.

REITZ, R. Palmeiras. . Flora Ilustrada Catarinense. Itajaí: 1974.

RODERJAN C. V. O Gradiente da Floresta Ombrófila Densa no Morro Anhangava, Quatro Barras, PR: aspectos climáticos, pedológicos e fitossociológicos. Curitiba: 1994. 119f. Tese (Doutorado em Ciências Florestais) - Setor de Ciências Agrárias, Universidade Federal do Paraná.

SOUZA, R. C. M.; CÂMARA NETO, G.; ALVES, D. S. O. Desenvolvimento de sistemas de informações geográfica e de processamento digital no INPE. In: SIMPÓSIO BRASILEIRO DE GEOPROCESSAMENTO. 1. 1990 São Paulo: Anais... Escola Politécnica/USP. 1990. p. 168173.

SPURR, S. H.; BARNES, B. V. Ecologia Florestal. México, D.F.: AGT, 1982. 690 p.

STEEL, R. G.; TORRIE, J. H. Principles and procedures on statistics. New York: MsGraw-Hill, 1960. 481p.

SUSILAWATI, S.; WEIR, M. J. C. GIS applications in forest land management in Indonesia. ITC Journal, New York: n. 3, p. 236-244, 1988.
TRANQUILLINI, W. Physyological ecology of the alpine timberline. In Tree existence at high altitudes with special references to the European Alps. Berlin: Springer, 1979. p. 131. (Ecological Studies 31).

UFPR; ITCF. Levantamento geomorfologico com ênfase em solos, na porção sul de tombamento da Serra do Mar. Curitiba: $1992.88 \mathrm{p}$.

VELOSO, H. P. \& KLEIN, R. M. As comunidades e associações vegetais da mata pluvial atlântica do sul do Brasil: Associação do Município de Brusque, Estado de Santa Catarina. Sellowia, Itajaí: n. 8, p. 81-235,1957.

VENTURI, N. L. GIS aplicado na área florestal. In: SEMINÁRIO DE ATUALIZAÇÃO EM SENSORIAMENTO REMOTO E SISTEMAS DE INFORMAÇÕES GEOGRÁFICAS APLICADAS À ENGENHARIA FLORESTAL, 4. Anais... Curitiba: Editorado por: Atilio Disperatti e Nelson Carlos Rosot. 2000. $186 \mathrm{p}$.

WEBER; E. Introdução a sistemas de informação geográfica. In: CONGRESSO BRASILEIRO DE CARTOGRAFIA， 20., 2001. Porto Alegre: Anais... Porto Alegre: Editorado em CD-ROOM, 41 p.

WENDLING, J. L. G. Modelos matemáticos de crescimento e de produção em biomassa para árvores de Euterpe edulis MART. plantadas a céu aberto. Curitiba: 1998. 168f. Dissertação (Mestrado em Ciências Florestais) - Setor de Ciências Agrárias, Universidade Federal do Paraná. 